\title{
The $\alpha$-Effect in $S_{N} A r$ Reaction of 1-Fluoro-2,4-dinitrobenzene with Hydrazine: Ground-State Destabilization versus Transition-State Stabilization
}

\author{
Hyo-Jin Cho ${ }^{\dagger}$ and Ik-Hwan Um* \\ Department of Chemistry and Nano Science, Ewha Womans University, Seoul 120-750, Korea. *E-mail: ihum@ewha.ac.kr \\ ${ }^{\dagger}$ Department of Chemistry, Duksung Women's University, Seoul 132-714, Korea \\ Received April 14, 2014, Accepted April 18, 2014
}

\begin{abstract}
A kinetic study is reported on $\mathrm{S}_{\mathrm{N}} \mathrm{Ar}$ reaction of 1-fluoro-2,4-dinitrobenzene with a series of primary amines including hydrazine in $\mathrm{H}_{2} \mathrm{O}$ at $25.0{ }^{\circ} \mathrm{C}$. The plots of $k_{\text {obsd }} v s$. [amine] are linear and pass through the origin, indicating that general-base catalysis by a second amine molecule is absent. The Brønsted-type plot exhibits an excellent linear correlation with $\beta_{\text {nuc }}=0.46$ when hydrazine is excluded from the correlation. The reaction has been suggested to proceed through a stepwise mechanism, in which expulsion of the leaving group occurs after the rate-determining step (RDS). Hydrazine is $c a$. 10 times more reactive than similarly basic glycylglycine (i.e., the $\alpha$-effect). A five-membered cyclic intermediate has been suggested for the reaction with hydrazine, in which intramolecular H-bonding interactions would facilitate expulsion of the leaving group. However, the enhanced leaving-group ability is not responsible for the $\alpha$-effect shown by hydrazine because expulsion of the leaving group occurs after RDS. Destabilization of the ground-state of hydrazine through the electronic repulsion between the nonbonding electron pairs is responsible for the $\alpha$-effect found in the current $S_{N} A r$ reaction.
\end{abstract}

Key Words : The $\alpha$-Effect, Hydrazine, $\mathrm{S}_{\mathrm{N}} \mathrm{Ar}$ reaction, H-bonding interaction, Brønsted-type plot

\section{Introduction}

The term $\alpha$-effect was given to the abnormally enhanced nucleophilic reactivity exhibited by nucleophiles possessing one or more nonbonding electron pairs at the atom $\alpha$ to the reaction site. ${ }^{1}$ Numerous studies have been carried out to account for the $\alpha$-effect phenomenon. ${ }^{2}$ Some important theories suggested as the origins of the $\alpha$-effect are (1) Destabilization of the ground-state (GS) due to the electronic repulsion between the nonbonding electron pairs, (2) Stabilization of the transition-state (TS), (3) Thermodynamic stability of reaction products, (4) Solvent effects. ${ }^{3-8}$

Studies on the $\alpha$-effect have focused mostly on acyl-group transfer reactions. Thus, only few reports are available for $\mathrm{S}_{\mathrm{N}} \mathrm{Ar}$ reactions of activated aromatic or heteroaromatic compounds with $\alpha$-effect nucleophiles, ${ }^{9}$ although $S_{N} A r$ reactions have a similarity to nucleophilic substitution reactions of carboxylic esters. The apparent similarity is the nucleophilic addition step in $S_{N} A r$ reaction and the addition step to carbonyl group in ester. In both cases addition to the $s p^{2}$ carbon leads to rehybridization to $s p^{3}$ to produce a tetrahedral intermediate. Elimination of the leaving group in subsequent $\operatorname{step}(\mathrm{s})$ restores the $s p^{2}$ carbon. A fundamental difference is that addition to a typical electron-deficient aromatic substrate in an $\mathrm{S}_{\mathrm{N}} \mathrm{Ar}$ reaction entails loss of aromaticity in the formation of the Meisenheimer complex. Accordingly, expulsion of the leaving group occurs rapidly after the RDS to regain the lost aromaticity in most cases.

We have recently reported that the $S_{N} A r$ reaction of 1fluoro-2,4-dinitrobenzenes (FDNB) with a series of secondary amines proceeds through a stepwise mechanism with

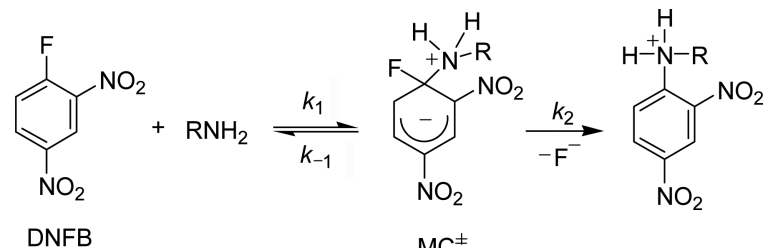

Scheme 1

one or two intermediates depending on the reaction medium. ${ }^{10}$ The $S_{N} A r$ reaction has been suggested to proceed through a stepwise mechanism with two intermediates in $\mathrm{MeCN}$ (e.g., a zwitterionic Meisenheimer complex $\mathrm{MC}^{ \pm}$and its deprotonated form $\left.\mathrm{MC}^{-}\right) .{ }^{10}$ However, the deprotonation process to form $\mathrm{MC}^{-}$from $\mathrm{MC}^{ \pm}$has been reported to be absent for the corresponding reaction carried out in $\mathrm{H}_{2} \mathrm{O},{ }^{10}$ indicating that the nature of the reaction medium governs the reaction mechanism.

Our study has now been extended to the $S_{N} A r$ reaction of FDNB with a series of primary amines (including hydrazine as an $\alpha$-effect nucleophile) in $\mathrm{H}_{2} \mathrm{O}$ to investigate the $\alpha$-effect in the $\mathrm{S}_{\mathrm{N}} \mathrm{Ar}$ reaction. The kinetic data in this study have been compared with those reported previously for the acyl-group transfer reaction of 4-nitrophenyl acetate (PNPA) with primary amines to obtain more information on the reaction mechanism and the origin of the $\alpha$-effect.

\section{Results and Discussion}

The kinetic study was performed under pseudo-first-order conditions in which the concentration of amines was kept in 
excess over the substrate concentration. All of the reactions in this study obeyed first-order kinetics and pseudo-firstorder rate constants $\left(k_{\text {obsd }}\right)$ were calculated from the equation, $\ln \left(A_{\infty}-A_{\mathrm{t}}\right)=-k_{\text {obsd }} t+C$. The plots of $k_{\text {obsd }} v s$. [amine] were linear and passed through the origin, indicating that generalbase catalysis by a second amine molecule is absent and contribution of $\mathrm{H}_{2} \mathrm{O}$ and/or $\mathrm{OH}^{-}$from hydrolysis of amines to $k_{\text {obsd }}$ is negligible. Thus, the second-order rate constants $\left(k_{\mathrm{N}}\right)$ were calculated from the slope of the linear plots. Based on replicate runs, it is estimated that the uncertainty in the $k_{\mathrm{N}}$ values is less than $\pm 3 \%$. The $k_{\mathrm{N}}$ values calculated in this way are summarized in Table 1 for the reactions of FDNB with primary amines together with those reported previously for the corresponding reactions of PNPA for comparison.

Reaction Mechanism. As shown in Table 1 , the $k_{\mathrm{N}}$ value for the aminolysis of FDNB decreases as the amine basicity decreases (except for hydrazine), e.g., it decreases from 29.2 $\times 10^{-2} \mathrm{M}^{-1} \mathrm{~s}^{-1}$ to $3.72 \times 10^{-2}$ and $1.88 \times 10^{-3} \mathrm{M}^{-1} \mathrm{~s}^{-1}$ as the $\mathrm{p} K_{\mathrm{a}}$ value of the conjugate acid of the amine decreases from 10.63 to 8.25 and 5.68 in turn. Hydrazine exhibits a larger $k_{\mathrm{N}}$ value than similarly basic glycylglycine, which is manifestation of the $\alpha$-effect. A similar result is demonstrated for the corresponding reaction of PNPA, although the dependence of $k_{\mathrm{N}}$ on the amine basicity is more significant for the reaction of PNPA than for that of FDNB. It is also notable that the $\alpha$-effect shown by hydrazine is much smaller for the reaction of FDNB $\left(k_{\mathrm{N}}^{\text {hydrazine }} / k_{\mathrm{N}}{ }^{\text {glycylglycine }}=10\right)$ than for that of PNPA $\left(k_{\mathrm{N}}^{\text {hydrazine }} / k_{\mathrm{N}}\right.$ glycylglycine $\left.=52\right)$.

Aminolysis of carboxylic esters has been reported to proceed through a concerted mechanism or via a stepwise pathway with one or two intermediates (e.g., a zwitterionic tetrahedral intermediate $\mathrm{T}^{ \pm}$and its deprotonated form $\mathrm{T}^{-}$) depending on the reaction conditions. ${ }^{13-16}$ Reaction of 2,4dinitrophenyl benzoate with a series of cyclic secondary amines has been reported to proceed through a stepwise mechanism with a change in rate-determining step (RDS) in $\mathrm{H}_{2} \mathrm{O}$ containing $20 \mathrm{~mol} \%$ DMSO on the basis of a curved Brønsted-type plot $^{15 a}$ but via a concerted mechanism in $\mathrm{MeCN}$ on the basis of a linear Brønsted-type plot with $\beta_{\text {nuc }}=$

Table 1. Summary of Second-Order Rate Constants for the Reactions of 1-Fluoro-2,4-dinitrobenzene (FDNB) and 4-Nitrophenyl Acetate (PNPA) with Primary Amines in $\mathrm{H}_{2} \mathrm{O}$ at $25.0 \pm 0.1^{\circ} \mathrm{C}$

\begin{tabular}{llccc}
\hline \multirow{2}{*}{ amine } & $\mathrm{p} K_{\mathrm{a}}{ }^{a}$ & \multicolumn{2}{c}{$10^{2} k_{\mathrm{N}} / \mathrm{M}^{-1} \mathrm{~s}^{-1}$} \\
\cline { 3 - 4 } & & $\mathrm{FDNB}$ & $\mathrm{PNPA}^{b}$ \\
\hline 1 ethylamine & 10.63 & 30.2 & 1350 \\
2 ethylenediamine & 9.98 & 33.1 & - \\
3 glycine & 9.76 & 19.5 & 261 \\
4 ethanolamine & 9.50 & 11.7 & 228 \\
5 & glycylglycine & 8.25 & 3.72 & 14.6 \\
6 hydrazine & 8.10 & 36.9 & 762 \\
7 glycine ethyl ester & 7.75 & 2.55 & 6.31 \\
8 trifluoroethylamine & 5.70 & 0.188 & 0.134 \\
9 aniline & 4.85 & - & 0.0210 \\
\hline
\end{tabular}

${ }^{a}$ The $\mathrm{p} K_{\mathrm{a}}$ data were taken from ref. $11 .{ }^{b}$ The kinetic data for the reactions of PNPA were taken from ref. 12.
$0.40{ }^{15 b}$ However, aminolysis of 4-pyridyl X-substitutedbenzoates has been suggested to proceed through a stepwise mechanism with two intermediates when the substituent $\mathrm{X}$ is a strong electron-withdrawing group (e.g., 4- $\mathrm{NO}_{2}, 4-\mathrm{CHO}$ and 4-CN) on the basis of the kinetic result that the plot of $k_{\text {obsd }} v s$. [amine] curves upward. ${ }^{16 a}$ In contrast, the corresponding reaction of 2-pyridyl X-substituted-benzoates has been concluded to proceed through a concerted mechanism regardless of the electronic nature of the substituent $\mathrm{X}$ on the basis of a linear Brønsted-type plot with $\beta_{\text {nuc }}=0.58$. ${ }^{16 \mathrm{~b}}$

$\mathrm{S}_{\mathrm{N}} \mathrm{Ar}$ reactions of FDNB with amines have been reported to proceed through a stepwise mechanism with one or two intermediates depending on the reaction conditions. ${ }^{10}$ Reaction of FDNB with secondary amines has been suggested to proceed through a stepwise mechanism with two intermediates in $\mathrm{MeCN}$ (e.g., $\mathrm{MC}^{ \pm}$and $\mathrm{MC}^{-}$), but the deprotonation process to form $\mathrm{MC}^{-}$from $\mathrm{MC}^{ \pm}$is absent for the reaction carried out in $\mathrm{H}_{2} \mathrm{O},{ }^{10}$ indicating that the nature of the reaction medium governs the reaction mechanism.

To investigate the reaction mechanism, Brønsted-type plots have been constructed for the reactions of FDNB and PNPA. As shown in Figure 1, the plots are linear with $\beta_{\text {nuc }}=$ 0.46 and 0.83 for the reactions of FDNB and PNPA, respectively, when the $k_{\mathrm{N}}$ and $\mathrm{p} K_{\mathrm{a}}$ values are statistically corrected using $p$ and $q$ ( $p=3$ and $q=1$ except $q=2$ for ethylenediamine). ${ }^{17}$

One can suggest that the aminolysis of PNPA proceeds through a stepwise mechanism, in which expulsion of the leaving group from $\mathrm{T}^{ \pm}$occurs in the RDS on the basis of the linear Brønsted-type plot with $\beta_{\text {nuc }}=0.83$. In contrast, the $\beta_{\text {nuc }}$ value of 0.46 is slightly larger than an upper limit of $\beta_{\text {nuc }}$ for reactions reported previously to proceed through a stepwise mechanism (e.g., $\beta_{\text {nuc }}=0.3 \pm 0.1$ ), in which expulsion of the leaving group occurs after the RDS. ${ }^{13}$ However, we propose that the $S_{N} A r$ reaction proceeds through $\mathrm{MC}^{ \pm}$, in which expulsion of the leaving group occurs rapidly after the RDS. This is because $\mathrm{F}^{-}$ion is less basic and a better nucleofuge than all the amines used in this study. Furthermore, the linear plot of $k_{\text {obsd }} v s$. [amine] as mentioned in the preceding
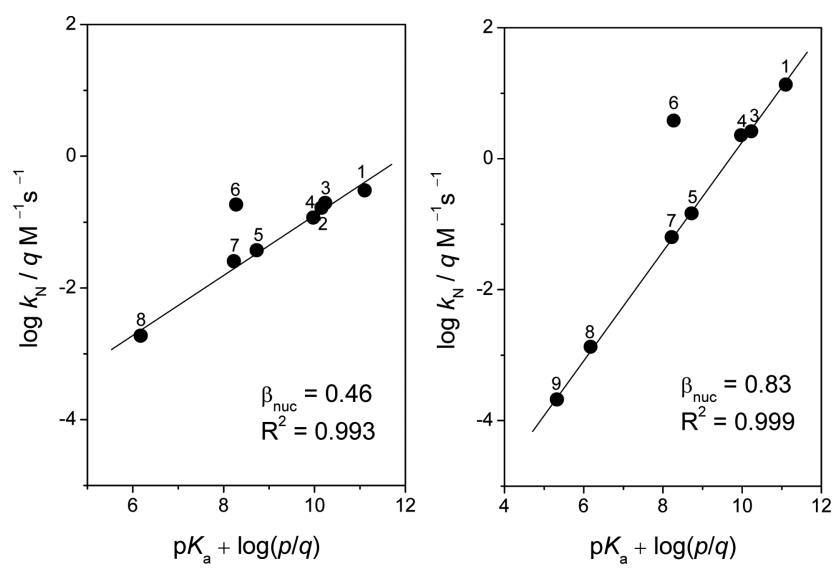

Figure 1. Brønsted-type plots for the aminloysis of 1-fluoro-2,4dinitrobenzene (FDNB) and 4-nitrophenyl acetate (PNPA) in $\mathrm{H}_{2} \mathrm{O}$ at $25.0 \pm 0.1{ }^{\circ} \mathrm{C}$. 
section indicates that general-base catalysis by a second amine molecule is absent (i.e., absence of the deprotonation process to form $\mathrm{M}^{-}$from $\mathrm{MC}^{ \pm}$).

Origin of the $\alpha$-Effect. Reactions of carboxylic esters with hydrazine have often been suggested to proceed through a TS structure similar to the intermediate (or TS) as modeled by I or II, in which the H-bonding interaction stabilizes the intermediate (or TS). ${ }^{2,18}$ Since such a cyclic intermediate is structurally not possible for the reaction of glycylglycine, stabilization of the intermediate (or TS) through the Hbonding interaction has been proposed as an origin of the $\alpha$ effect shown by hydrazine.

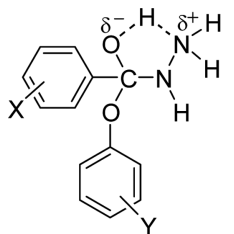

I

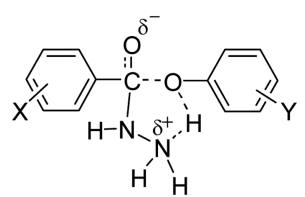

II
A four-membered cyclic intermediate has recently been proposed for $\mathrm{S}_{\mathrm{N}} \mathrm{Ar}$ reaction of $\mathrm{FDNB}$ with alkali-metal phenoxides $\left(\mathrm{PhO}^{-} \mathrm{M}^{+}, \mathrm{M}^{+}=\mathrm{Li}^{+}, \mathrm{Na}^{+}, \mathrm{K}^{+}\right) .{ }^{19}$ From a dispersion-corrected B3LYP density functional method, Jones et al. have revealed that the reaction proceeds through an intermediate III, in which $\mathrm{M}^{+}$ion facilitates expulsion of the leaving group (i.e., $\mathrm{F}^{-}$ion). ${ }^{19}$ Thus, one might suggest that the current reaction would proceed also through a cyclic intermediate as modeled by IV. It is apparent that expulsion of the leaving group from IV could be facilitated through the $\mathrm{H}$-bonding interaction. Since such five-membered cyclic intermediate IV is structurally not possible for the reaction of glycylglycine, one might suggest that the $\alpha$-effect shown by hydrazine in this study is due to an increase in nucleofugality of the leaving group through the H-bonding interaction. However, we propose that the enhanced nucleofugality through the H-bonding interaction in IV cannot be an origin of the $\alpha$-effect. Because the enhanced nucleofugality would not increase the overall reaction rate for the current reaction in which expulsion of the leaving group occurs after the RDS.

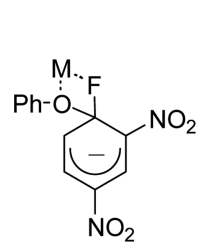

III

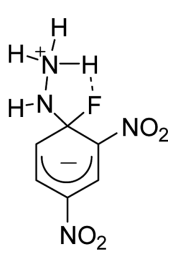

IV
Stabilization of TS or products has been reported as an origin of the $\alpha$-effect for reactions proceeding through a late TS (or a product-like TS). ${ }^{2}$ However, the effect of TS (or product) stabilization would be insignificant for reactions which proceed through an early TS (or a reactant-like TS). It is notable that the $\beta_{\text {nuc }}$ values are 0.46 and 0.83 for the reactions of FDNB and PNPA, respectively. This indicates that the reaction of FDNB proceeds through an early TS while that of PNPA proceeds through a late TS. Thus, one can suggest that the $\alpha$-effect for the reaction of FDNB with hydrazine is not due to stabilization of the TS (or the intermediate IV) through the H-bonding interaction.

The above argument is consistent with the small $\alpha$-effect found for the reaction of FDNB. Table 1 shows that the $\alpha$ effects $\left(k_{\mathrm{N}}^{\text {hydrazine }} / k_{\mathrm{N}}{ }^{\text {glycylglycine }}\right)$ are 10 and 52 for the reactions of FDNB and PNPA, respectively. The $\alpha$-effect for the reaction of FDNB is quite small but appears to be in accord with the reports that the magnitude of the $\alpha$-effect decreases with decreasing the $\beta_{\text {nuc }}$ value. ${ }^{2}$ The $\beta_{\text {nuc }}$ value of 0.46 implies that the $\mathrm{S}_{\mathrm{N}} \mathrm{Ar}$ reaction proceeds through a reactant-like TS. In this case, the GS energy should be an important factor that controls the reactivity. Since the GS of hydrazine is known to be destabilized by the electronic repulsion between the nonbonding electron pairs on the two adjacent $\mathrm{N}$ atoms, we propose that destabilization of the GS of hydrazine is responsible for the $\alpha$-effect in the $S_{N} A r$ reaction of FDNB with hydrazine.

\section{Conclusions}

The current study has led us to conclude the following: (1) The Brønsted-type plots for the reactions of FDNB and PNPA are linear with $\beta_{\text {nuc }}=0.46$ and 0.83 , respectively. (2) The reaction of FDNB proceeds through a stepwise mechanism in which expulsion of the leaving group occurs after the RDS, while that of PNPA proceeds through a stepwise pathway in which expulsion of the leaving group occurs in the RDS. (3) The reaction of FDNB is proposed to proceed through a cyclic intermediate IV, in which the H-bonding interaction could facilitate expulsion of the leaving group. (4) However, the enhanced leaving-group ability through the $\mathrm{H}$-bonding interaction is not an origin of the $\alpha$-effect due to the nature of the RDS in the current $\mathrm{S}_{\mathrm{N}} \mathrm{Ar}$ reaction. (5) Destabilization of the GS of hydrazine through the electronic repulsion is responsible for the small $\alpha$-effect found in the $\mathrm{S}_{\mathrm{N}} \mathrm{Ar}$ reaction of FDNB.

\section{Experimental}

Materials. Doubly glass distilled water was further boiled and cooled under nitrogen just before use. 1-Fluoro-2,4-dinitrobenzene, primary amines and the other chemicals were of the highest quality available.

Kinetics. The kinetic study was performed using a UV-vis spectrophotometer equipped with a constant temperature circulating bath. The reactions were followed by monitoring the appearance of $\mathrm{N}$-(2,4-dinitrophenyl)amine derivatives. All reactions were carried out under pseudo-first-order conditions in which the amine concentration was at least 20 times greater than the substrate concentration. The amine stock solution was prepared by dissolving 2 equiv. of aminehydrochloride and 1 equiv. of standardized $\mathrm{NaOH}$ solution to make a self-buffered solution in a $25.0 \mathrm{~mL}$ volumetric flask. 
Products Analysis. N-(2,4-Dinitrophenyl)hydrazine was identified as one of the products in the reaction of FDNB with hydrazine by comparison of the UV-vis spectra after completion of the reaction with the authentic sample under the same reaction conditions.

Acknowledgments. This work was supported by Basic Science Research Program through the National Research Foundation of Korea (NRF) funded by the Ministry of Education (2012-R1A1B-3001637).

\section{References}

1. Edwards, J. O.; Pearson, R. G. J. Am. Chem. Soc. 1962, 84, 16-24.

2. Reviews: (a) Buncel, E.; Um, I. H.; Terrier, F. The Chemistry of Hydroxylamines, Oximes and Hydroxamic Acids; Wiley Press: West Sussex, 2009; Chapter 17. (b) Buncel, E.; Um, I. H. Tetrahedron 2004, 60, 7801-7825. (c) Hoz, S.; Buncel, E. Israel J. Chem. 1985, 26, 313-319. (d) Grekov, A. P.; Veselov, V. Y. Russ. Chem. Rev. 1978, 47, 631-648.

3. (a) Terrier, F.; Rodriguez-Dafonte, P.; Le Guevel, E.; Moutiers, G. Org. Biomol. Chem. 2006, 4, 4352-4363. (b) Terrier, F.; Le Guevel, E.; Chatrousse, A. P.; Moutiers, G.; Buncel, E. Chem. Commun. 2003, 600-601. (c) Buncel, E.; Cannes, C.; Chatrousse, A.-P.; Terrier, F. J. Am. Chem. Soc. 2002, 124, 8766-8767.

4. (a) Kamps, J. A. G.; Belle, R.; Mecinovic, J. Org. Biomol. Chem. 2013, 11, 1103-1108. (b) Kirby, A. J.; Davies, J. E.; Fox, D. J.; Hodgson, D. R.; Goeta, A. E.; Lima, M. F.; Priebe, J. P.; Santaballa, J. A.; Nome, F. Chem. Commun. 2010, 1302-1304. (c) Kirby, A. J.; Tondo, D. W.; Medeiros, M.; Souza, B. S.; Priebe, J. P.; Lima, M. F.; Nome, F. J. Am. Chem. Soc. 2009, 131, 2023-2028. (d) Kirby, A. J.; Souza, B. S.; Medeiros, M.; Priebe, J. P.; Manfredi, A. M.; Nome, F. Chem. Commun. 2008, 4428-4429. (e) Kirby, A. J.; Lima, M. F.; da Silva, D.; Roussev, C. D.; Nome, F. J. Am. Chem. Soc. 2006, 128, 16944-16952.

5. (a) Patterson, E. V.; Fountain, K. R. J. Org. Chem. 2006, 71, 81218125. (b) Fountain, K. R. J. Phys. Org. Chem. 2005, 18, 481-485. (c) Fountain, K. R.; Felkerson, C. J.; Driskell, J. D.; Lamp, B. D. J. Org. Chem. 2003, 68, 1810-1814. (d) Fountain, K. R.; Tad-y, D. B.; Paul, T. W.; Golynskiy, M. V. J. Org. Chem. 1999, 64, 65476553. (e) Fountain, K. R.; Patel, K. D. J. Org. Chem. 1997, 62, 4795-4797.

6. (a) McAnoy, A. M.; Paine, M. R.; Blanksby, S. J. Org. Biomol. Chem. 2008, 6, 2316-2326. (b) Liang, J.-X.; Geng, Z. Y.; Wang, Y. C. J. Comput. Chem. 2012, 33, 595-606. (c) Wei, X. G.; Sun, X. M.; Wu, W. P.; Ren, Y.; Wong, N. B.; Li, W. K. J. Org. Chem. 2010, 75, 4212-4217. (d) Ren, Y.; Yamataka, H. J. Comput. Chem. 2009, 30, 358-365. (e) Ren, Y.; Yamataka, H. J. Org. Chem. 2007, 72, 5660-5667. (f) Ren, Y.; Yamataka, H. Chem. Eur. J. 2007, 13, 677-682. (g) Ren, Y.; Yamataka, H. Org. Lett. 2006, 8, 119-121.

7. (a) Thomsen, D. L.; Reece, J. N.; Nichols, C. M.; Charles, M.; Hammerum, S.; Bierbaum, V. M. J. Am. Chem. Soc. 2013, 135, 15508-15514. (b) Villano, S. M.; Eyet, N.; Lineberger, W. C.;
Bierbaum, V. M. J. Am. Chem. Soc. 2009, 131, 8227-8233. (c) Garver, J. M.; Gronert, S.; Bierbaum, V. M. J. Am. Chem. Soc. 2011, 133, 13894-13897. (d) Garver, J. M.; Yang, Z.; Nichols, C. M.; Worker, B. B.; Gronert, S.; Bierbaum, V. M. Int. J. Mass Spectrom. 2012, 316-318, 244-250. (e) Garver, J. M.; Yang, Z.; Wehres, N.; Nichols, C. M.; Worker, B. B.; Gronert, S.; Bierbaum, V. M. Int. J. Mass Spectrom. 2012, 330-332, 182-190.

8. (a) Um, I. H.; Kang, J. S.; Kim, M. Y.; Buncel, E. J. Org. Chem. 2013, 78, 8689-8695. (b) Um, I. H.; Han, J. Y.; Buncel, E. Chem. Eur. J. 2009, 15, 1011-1017. (c) Um, I. H.; Kim, E. H.; Lee, J. Y. J. Org. Chem. 2009, 74, 1212-1217. (d) Um, I. H.; Hwang, S. J.; Buncel, E. J. Org. Chem. 2006, 71, 915-920. (e) Um, I. H.; Shin, Y. H.; Han, J. Y.; Buncel, E. Can. J. Chem. 2006, 84, 1550-1556. (f) Um, I. H.; Hong, J. Y.; Buncel, E. Chem. Commun. 2001, 2728. (g) Um, I. H.; Buncel, E. J. Am. Chem. Soc. 2001, 123, 1111111112. (h) Um, I. H.; Buncel, E. J. Org. Chem. 2000, 65, 577-582. (i) Um, I. H.; Park, Y. M.; Buncel, E. Chem. Commun. 2000 1917-1918.

9. (a) Rougier, N. M.; Vico, R. V.; de Rossi, R. H.; Bujan, E. I. $J$ Org. Chem. 2010, 75, 3427-3436. (b) Han, X.; Balakrishnan, V. K.; van Loon, G. W.; Buncel, E. Langmuir 2006, 22, 9009-9017. (c) Moutiers, G.; Le Guevel, E.; Cannes, C.; Terrier, F.; Buncel, E. Eur. J. Org. Chem. 2001, 3279-3284.

10. (a) Um, I. H.; Im, L. R.; Kang, J. S.; Bursey, S. S.; Dust, J. M. J. Org. Chem. 2012, 77, 9738-9746. (b) Um, I. H.; Min, S. W.; Dust, J. M. J. Org. Chem. 2007, 72, 8797-8803.

11. (a) Jencks, W. P.; Regenstein, J. In Handbook of Biochemistry, $2^{\text {nd }}$ ed.; Sober, H. A., Ed.; Chemical Rubber Publishing Co.: Cleveland, OH, 1970; p J-203. (b) Gilchrist, M.; Jencks, W. P. J. Am. Chem. Soc. 1968, 90, 2622-2637.

12. Um, I. H.; Choi, K. E.; Kwon, D. S. Bull. Korean Chem. Soc. 1990, 11, 362-364.

13. Reviews: (a) Castro, E. A. Pure Appl. Chem. 2009, 81, 685-696. (b) Castro, E. A. J. Sulfur Chem. 2007, 28, 401-429. (c) Castro, E. A. Chem. Rev. 1999, 99, 3505-3524. (d) Jencks, W. P. Chem. Rev. 1985, 85, 511-527. (e) Jencks, W. P. Chem. Soc. Rev. 1981, 10, 345-375.

14. (a) Pavez, P.; Millan, D.; Morales, J. I.; Castro, E. A. J. Org. Chem. 2013, 78, 9670-9676. (b) Castro, E. A.; Aliaga, M.; Campodonico, P. R.; Cepeda, M.; Contreras, R.; Santos, J. G. J. Org. Chem. 2009, 74, 9173-9179.

15. (a) Um, I. H.; Kim, K. H.; Park, H. R.; Fujio, M.; Tsuno, Y. J. Org. Chem. 2004, 69, 3937-3942. (b) Um, I. H.; Jeon, S. E.; Seok, J. A. Chem. Eur. J. 2006, 12, 1237-1243.

16. (a) Um, I. H.; Bea, A. R. J. Org. Chem. 2012, 77, 5781-5787. (b) Um, I. H.; Bea, A. R. J. Org. Chem. 2014, 79, 1206-1212.

17. Bell, R. P. The Protom in Chemistry; Methuem: London, 1959; $p$ 159.

18. (a) Um, T. I.; Kim, M. Y.; Kim, T. E.; Um, I. H. Bull. Korean Chem. Soc. 2014, 35, 436-440. (b) Kim, M. Y.; Kim, T. E.; Lee, J. E.; Um, I. H. Bull. Korean Chem. Soc. 2014, 35, 2271-2276.

19. Jones, G. O.; Somaa, A. A.; O’Brien, J. M.; Albishi, H.; Al-Megren, H. A.; Alabdulrahman, A. M.; Alsewailem, F. D.; Hedrick, J. L.; Rice, J. E.; Horn, H. W. J. Org. Chem. 2013, 78, 5436-5443. 